\title{
Evaluating an Interspecific Helianthus annuus $\times$ Helianthus nuttallii Line for Use in Sunflower Breeding Program
}

\author{
Roumiana Vassilevska-Ivanova ${ }^{1^{*}}$, Ira Stancheva ${ }^{2}$, Maria Geneva $^{2}$, Zoya Tcekova $^{1}$ \\ ${ }^{I}$ Department of Applied Genetics and Biotechnology, Institute of Plant Physiology and Genetics, Bulgarian Academy of Sciences Akad. \\ Georgy Bontchev Str., Bl 21, 1113 Sofia, Bulgaria \\ ${ }^{2}$ Department of Plant Mineral Nutrition and Water Relation, Institute of Plant Physiology and Genetics, Bulgarian Academy of Sciences \\ Akad. Georgy Bontchev Str., Bl 21, 1113 Sofia, Bulgaria \\ AR T I C LE INFO A B S T R A C T

\section{Research Article} \\ Received 13 June 2017 \\ Accepted 05 June 2018

\section{Keywords.} \\ Antioxidants \\ Enzymes \\ Gene Transfer \\ Pre-breeding Line \\ Wide Hybridization \\ Interspecific cross was made between the common sunflower inbred line HA89 and an \\ accession of wild Helianthus nuttallii $(2 \mathrm{n}=2 \mathrm{x}=34)$ resistant to the most harmful disease \\ complex and tolerant to drought and high temperature. The recombinant inbred line was a \\ $\mathrm{BC}_{1} \mathrm{~F}_{15}$ progeny. The most remarkable feature observed was the vigorous plant habit that \\ manifests itself in measurable morphological characters such as increment plant height, \\ stem diameter and diameter of the head. The line was non-branched (monocephalic) \\ without anthocyanin pigmentation and possessed good agronomic characteristics. Along \\ with the morphological and reproductive traits, some biochemical characteristics related \\ to antioxidant activity were associated to wide hybridization. The overall characteristics \\ of HA-Hnutt line make it a useful plant material for research on interspecific \\ hybridization in Helianthus genus.
}

\footnotetext{
*Corresponding Author:

E-mail: ru_vas_bg@yahoo.com
}

DOI: https://doi.org/10.24925/turjaf.v6i12.1684-1689.1361

\section{Introduction}

During the last few years, there has been an increasing interest in the use of wild sunflower relatives in particular breeding programs which aim was providing useful materials to support practical breeding strategies. To produce potential new cultivars, interspecific and intergeneric hybridizations have been performed between common $H$. annuus and its wild relatives (Faure et al., 2002; Breton et al., 2012; Vassilevska-Ivanova et al., 2013; Vassilevska- Ivanova et al., 2014; VassilevskaIvanova et al., 2015; Liu et al., 2017; Seiler et al., 2017). Helianthus is a diverse genus comprised of 51 species with 14 annual and 37 perennial, all native to North America (Shilling, 2006). The very narrow genetic base of common sunflower has been broadened by the infusion of genes from wild species, which continue to be a valuable source of desirable agronomic traits. Helianthus nuttallii T. \& G. $(2 \mathrm{n}=2 \mathrm{x}=34)$ (Nuttal sunflower) was involved in our hybridization program since it appears to display an immune tolerance to Sclerotinia in USDA genetic stocks (Feng et al., 2007; Seiler et al., 2017), resistance to the most harmful disease complex (Seiler and Marek, 2011), and also it has shown to have drought tolerance caused by water deficit under field condition (Seiler et al., 2017).
In the course of our study on wide hybridization in sunflower, we obtained a number of recombinant inbred lines distinguishing from both parental species. Notably, some of these lines could be used as a pre-breeding plant material in many modern breeding programs that make substantial use of wild relatives.

Herewith, we report the results of interspecific hybridization Helianthus annuus $\times$ Helianthus nuttallii, in particular, development of a recombinant inbred line produced by conventional cross. The effect on antioxidant capacity as well as the content of the antioxidants such as ascorbate, tocopherols, phenols and flavonoids, and antioxidant enzymes was investigated.

\section{Materials and Methods}

\section{Plant Material}

The interspecific line $H$. annuus $\times H$. nuttallii originated from pollination of cytoplasmic male sterile (cms) line HA89 (female), a public oilseed sunflower inbred maintainer line released by US Department of Agriculture-Agricultural Research Service, with bulked pollen from wild perennial Helianthus nuttallii (male). The population of $H$. nuttallii was grown from seeds 
originally obtained from the experimental garden located at Bloomington (Indiana), USA. The cross was made using the conventional hybridizing method. Each experiment was carried out on flower head that had been protected from foreign pollen by bagging. Firstgeneration hybrid plants were verified using morphological and cytological methods, and $F_{1}$ hybrids were back-crossed to common sunflower to obtain $\mathrm{BC}_{1}$. Some $\mathrm{BC}_{1}$ progeny revealed a vigorous phenotype which was considered as valuable for further breeding. These plants were selected for and fixed after the $\mathrm{BC}_{1}$ to produce an interspecific line (namely HA-Hnutt). Seeds from advanced plant generations were produced after selfpollination under a bag. The plants growth conditions that were employed have already been described (VassilevskaIvanova and Naidenova, 2005). The line represented here is $F_{15}$ progeny of selfed plants; it was raised in the Experimental Field of the Institute of Plant Physiology and Genetics, Sofia, Bulgaria (located at $42^{\circ} 50^{\prime} \mathrm{N}, 23^{\circ} 00^{\prime}$ E, $595 \mathrm{~m}$ above the sea level) during 2011-2016. Seeds were sown in $5 \mathrm{~m}$ rows spaced $0.70 \mathrm{~cm}$ apart with three replications. The sowings were performed in late-April. Conventional management practices were used.

\section{Phenotypic Observations}

The morphological traits were recorded of thirty random plants for hybrid line and its parent. Methods used in this investigation for hybridizing plants, fertility tests and morphological comparisons are the same as those described in previous report (Vassilevska-Ivanova and Naidenova, 2005). The following phenotype traits were recorded: plant height $(\mathrm{cm})$, head diameter $(\mathrm{cm})$, days to flowering $(50 \%)$, days to maturity $(50 \%)$, pollen staining using the acetocarmine test, thousand seeds weight (TSW) (g), and the kernel ratio (\%) using the equation: Kernel ratio $(\%)=$ kernel weight $(\mathrm{g}) /$ grain weight $(\mathrm{g}) \times 100$. Morphological floral characteristics included the number of ray flowers, the length of the corolla of ray flowers $(\mathrm{cm})$, and the width of the corolla of ray flowers $(\mathrm{cm})$. All floral characteristics were measured at the end of anthesis.

\section{Antioxidant Enzyme Analyses}

Enzyme extracts were prepared by homogenizing plants tissue in a pre-chilled mortar in $20 \mathrm{ml}$ chilled extraction buffer ( $\mathrm{pH}$ 7.8). Extracts were then centrifuged at $12000 \mathrm{~g}$ for $30 \mathrm{~min}$ at $5^{\circ} \mathrm{C}$. Enzyme assays were conducted immediately following extraction. Superoxide dismutase (SOD) (EC 1.15.1.1) was measured by photochemical method described by Giannopolitis and Ries (1977). Assays were carried out under illumination. One unit of SOD activity was defined as the amount of enzyme required to cause $50 \%$ inhibition of the rate of pnitro blue tetrazolium chloride reduction at $560 \mathrm{~nm}$. Catalase (CAT) (EC 1.11.1.6) activity was assayed in a method following Beers and Sizer (1952) with minor modifications. Activity was determined by following decomposition of $\mathrm{H}_{2} \mathrm{O}_{2}$ (extinction coefficient, $39.4 \mathrm{mM}^{-1}$ $\mathrm{cm}^{-1}$ ) at $240 \mathrm{~nm}$. The enzyme activity was expressed in catalytic units-mmol $\mathrm{H}_{2} \mathrm{O}_{2} \mathrm{~mL}^{-1} \mathrm{~min}^{-1}$ per $\mathrm{mg}$ protein. Guaiacol peroxidase (GPO) (EC 1.11.1.7) activity was determined according to Urbanek et al. (1991). The oxidation of guaiacol in the presence of $\mathrm{H}_{2} \mathrm{O}_{2}$ was measured as the increase in absorbance recorded at 470 $\mathrm{nm}$. The enzyme activity was expressed as nmol $\mathrm{H}_{2} \mathrm{O}_{2} \mathrm{mg}$ protein $^{-1} \mathrm{~min}^{-1}$ (Plewa et al. 1991). Ascorbate peroxidase (APX) (EC 1.11.1.1) activity was determined measured according to the method of Nakano and Asada (1981). The concentration of oxidized ascorbate was calculated by the decrease in absorbance at $290 \mathrm{~nm}$. Enzyme activity was quantified using the molar extinction coefficient for ascorbate $\left(2.8 \mathrm{mM}^{-1} \mathrm{~cm}^{-1}\right)$, and was expressed as moles of ascorbate oxidized per milligram of protein per minute (McKersie and Leshem 1994). Soluble protein content was determined by the method of Bradford (1976) using bovine serum albumin as a standard.

\section{Antioxidant Capacity}

The total antioxidant capacity in fresh leaves was measured from bleaching of the purple coloured methanol solution of free stable radical by the method of Tepe et al. (2006). Antioxidant capacity of the sample was calculated using the equation:

$$
\% \text { Antioxidant activity }(\mathrm{I})=\left(\mathrm{A}_{\text {blank }}-\mathrm{A}_{\text {sampe }} / \mathrm{A}_{\text {blank }}\right) \times 100
$$

Where $A_{\text {blank }}$ is the absorbance of the control sample (containing all reagents except the test compound), and $\mathrm{A}_{\text {sample }}$ is the absorbance of plant extracts.

The concentration of total phenols in the extracts was measured spectrofotometrically by Folin-Ciocalteu method and calculated as caffeic acid equivalents (Pfeffer et al. 1998). The results were expressed in milligrams of caffeic acid per gram of dry weight. The total flavonoids content was measured spectrofotometrically by the method of Zhishen et al. (1999) using a standard curve with catechin as the standard. Total flavonoids content was expressed in milligrams of catechin equivalents per gram of dry weight.

\section{Statistical analysis}

Data were subjected to one-way ANOVA analysis of variance for comparison of means, and significant differences were calculated according to Fisher LSD test at the 5\% level using a statistical software package (Statigraphics Plus, version 5.1 for Windows).

\section{Results}

\section{Phenotype Characteristic and Agronomic Traits}

The morphological features of both parental genotypes and the selected line $(H$. annuus $\times H$. nuttallii) were assessed (Table 1). In many respects the developing hybrid line revealed intermediacy to the parental species. At maturity, the all plants definitely distinguished in comparison with its parents showing vegetative vigor and increment in the growth in height and in the head diameter (Table 1). The leaves were usually well developed, dark green, mostly alternate of $H$. annuus type with deltoid shape and entire leaf margin. As the whole, line HA-Hnutt had more above ground vegetative biomass and smaller seeds than $H$. annuus. The time to bloom $(50 \%)$ was accelerated by $10 \%$ in the hybrid plants compared with the cultivated sunflower line. The earlier flowering may be attributed to developmental changes that presumably resulted after interspecific 
hybridization, suggesting that it should be possible to breed for the sunflower plants with reduced crop production time (Warner and Walworth, 2010). Furthermore, the line HA-Hnutt has a high degree of pollen stainability (about 93\%) which is a measure in hybridization studies as a proxy for true pollen viability; the pollen grains are typically formed and well stained (Table1).

In common sunflower, $H$. annuus, the number of outer flowers of the head (ray or ligulate flowers) can be considered to be a specific qualitative trait characterizing putative hybrids (Fambrini et al., 2003). In our case, the plants produced inflorescences and flowers with normal structure intermediate in size (smaller than $H$. annuus but larger than $H$. nuttallii); differences in the number of ray flowers and width of corolla of ray flowers became apparent between both parents $(H$. annuus and $H$. nuttallii) and the selected line, thus indicating that the change in the floral characteristics in hybrid plants was restricted to ray flowers (Table 1).

\section{Antioxidant Capacity and Antioxidant Enzymes}

Among the all three genotypes tested, the DPPH radical scavenging activity varied from 61.15 to $93.12 \%$ in the leaves, and from 78.22 to $93.48 \%$, in the flowers (HA 89 line and hybrid line), respectively (Table 2). FRAP of investigated genotypes varied from 11.060 to $41.883 \mu \mathrm{mol} \mathrm{Fe}^{2+} \mathrm{g}^{-1} \mathrm{DW}$ in the leaves (line and $H$. annuus HA 89), and from 25.928 to $46.779 \mu \mathrm{mol} \mathrm{Fe}^{2+} \mathrm{g}^{-1}$ DW in the flowers, respectively. Both DPPH and FRAP methods together give a good estimate of the antioxidant potential of the studied plants, acting by different mechanisms. In the current study, the total antioxidant activity of leaves and flowers extracts measured by FRAP was found to be much lower than either parental samples. Alternatively, the level of antioxidants as measured by DPPH was higher in the hybrid line compared with the common sunflower line and wild parent $H$. nuttallii.

The amount of total phenolics varied slightly in plant materials and ranged from 6.647 to $8.849 \mathrm{mg}$ of caffeic acid/g dry sample in the leaves, and from 5.996 to 8.144 $\mathrm{mg}$ of caffeic acid/g dry sample in the ray flowers, respectively (Table 2). The highest amount was found in HA-Hnutt line, and the lowest in the cultivated sunflower $H$. annuus. The flavonoid contents in the leaves and ray flowers of both parents and hybrid line are given in Table 2. In the leaves, HA-Hnutt line had higher value of 13.843 mg catechin/g dry sample and $H$. annuus had the lowest value of $11.819 \mathrm{mg}$ catechin/g dry sample, respectively. The difference in the content of tocopherols is clearly expressed in the leaves of HA-Hnutt line and between parents as $H$. annuus has markedly low content (Table 2). In hybrid line, total ascorbic acid (vitamin $\mathrm{C}$ ) concentration in the leaves as well as in the ray flowers was significantly lower than in common sunflower and wild $H$. nuttallii (Table 2).

Table 1 Agronomic characteristics of H. annuus HA 89, H. nuttallii and interspecific line H. annuus $\times$ H. nuttallii

\begin{tabular}{|c|c|c|c|}
\hline \multirow{2}{*}{ Characters } & H. nuttallii & Line (hybrid) & H. annuus HA 89 \\
\hline & mean $\pm \mathrm{SD}^{* *}$ & mean \pm SD & mean \pm SD \\
\hline \multicolumn{4}{|l|}{ Flowering } \\
\hline Days to bloom $(50 \%)$ & 70 & 64 & 71 \\
\hline Self-compatibility (\%) & 50 & 40 & 0 \\
\hline Pollen staining $(\%)$ & 93 & 93 & pollenless \\
\hline Plant height at flowering $(\mathrm{cm})$ & $245.0 \pm 3.95$ & $185.8 \pm 1.15$ & $153.6 \pm 0.81$ \\
\hline $\lim$ & $235-255$ & $182-190$ & $145-160$ \\
\hline Number of branches & highly branched & 0 & 0 \\
\hline \multicolumn{4}{|l|}{$\lim$} \\
\hline Stem width, cm & $1 \pm 0.01$ & $4.6 \pm 0.06$ & $3.2 \pm 0.02$ \\
\hline $\lim$ & $0.9-1.1$ & $4.5-4.8$ & $3-3.8$ \\
\hline \multicolumn{4}{|l|}{ Floral morphology } \\
\hline Flower colour & sunny yellow & sunny yellow & sunny yellow \\
\hline Disc colour & light & light & light \\
\hline Number of ray flowers & $15.33 \pm 0.61$ & $29.8 \pm 0.6$ & $47.1 \pm 1.23$ \\
\hline $\lim$ & $16-22$ & $27-33$ & $42-54$ \\
\hline Length of the corolla of the ray flowers (mm) & $1.77 \pm 0.03$ & $5.82 \pm 0.29$ & $9.54 \pm 0.11$ \\
\hline $\lim$ & $1.7-1.9$ & $5.4-6.4$ & $8.9-9.1$ \\
\hline Width of the corolla of the ray flower (mm) & $0.75 \pm 0.02$ & $1.93 \pm 0.04$ & $2.49 \pm 0.04$ \\
\hline 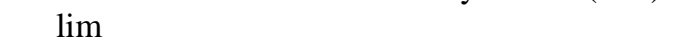 & $0.7-0.8$ & $1.0-1.2$ & $2.3-2.7$ \\
\hline Number of leaves & & $21.4 \pm 0.78$ & $31 \pm 1.2$ \\
\hline $\lim$ & & $19-28$ & $25-37$ \\
\hline \multicolumn{4}{|l|}{ Maturity } \\
\hline *Head diameter $(\mathrm{cm})$ & $1.23 \pm 0.02$ & $30.9 \pm 0.55$ & $24.2 \pm 0.36 \mathrm{a}$ \\
\hline $\lim$ & $1.2-1.3$ & $5-7$ & $21-26$ \\
\hline Days to maturity $(50 \%)$ & 170 & 139 & 162 \\
\hline \multicolumn{4}{|l|}{ Post harvest } \\
\hline 1000 seed weight $(\mathrm{g})$ & $3.02 \pm 0.46 \mathrm{a}$ & $63.6 \pm 1.07$ & $77.4 \pm 2.38$ \\
\hline Kernel ratio $(\%)$ & 0 & 40.09 & 66.92 \\
\hline
\end{tabular}


Table 2 Antioxidant capacity of an interspecific line H. annuus x H. Nuttallii*

\begin{tabular}{|c|c|c|c|c|}
\hline \multirow{2}{*}{ Parents and hybrid } & \multicolumn{2}{|c|}{ FRAP $\left(\mu \mathrm{mol} \mathrm{Fe} e^{2}+\mathrm{g}^{-1} \mathrm{DW}^{-1}\right)$} & \multicolumn{2}{|c|}{ DPPH $(\%)$} \\
\hline & Leaves & Ray flowers & Leaves & Ray flowers \\
\hline H. annuus & $41.883 \mathrm{a}$ & $46.779 \mathrm{bc}$ & $61.15 \mathrm{a}$ & $78.22 \mathrm{a}$ \\
\hline H. nuttallii & $33.996 b$ & $41.702 b$ & $83.00 \mathrm{~b}$ & $83.09 \mathrm{a}$ \\
\hline \multirow[t]{3}{*}{ Hybrid } & $11.060 \mathrm{a}$ & $25.928 \mathrm{a}$ & $93.12 b c$ & $93.48 \mathrm{ab}$ \\
\hline & \multicolumn{2}{|c|}{ Phenols (mg/g DW) } & \multicolumn{2}{|c|}{ Flavonoids (mg/g DW) } \\
\hline & Leaves & Ray flowers & Leaves & Ray flowers \\
\hline H. annuus & $6.647 \mathrm{a}$ & $5.996 \mathrm{a}$ & $11.819 \mathrm{a}$ & $8.309 a$ \\
\hline H. nuttallii & $7.200 \mathrm{ab}$ & $7.981 b$ & $12.505 b$ & $13.534 \mathrm{a}$ \\
\hline \multirow[t]{3}{*}{ Hybrid } & $8.849 \mathrm{~b}$ & $8.144 \mathrm{~b}$ & $13.843 \mathrm{c}$ & $9.601 \mathrm{a}$ \\
\hline & \multicolumn{2}{|c|}{ WS-AOC $\left(\mu \mathrm{mol} \mathrm{g}^{1}{ }^{1} \mathrm{DW}-^{1}\right)$} & \multicolumn{2}{|c|}{ LS-AOC $\left(\mu \mathrm{mol} \mathrm{g-}^{1} \mathrm{DW}_{-1}{ }^{1}\right)$} \\
\hline & Leaves & Ray flowers & Leaves & Ray flowers \\
\hline H. annuus & $248.471 b$ & $495.059 \mathrm{~b}$ & $0.650 \mathrm{a}$ & $0.800 \mathrm{a}$ \\
\hline H. nuttallii & $473.412 \mathrm{c}$ & $611.765 c$ & $1.150 \mathrm{~b}$ & $0.950 \mathrm{a}$ \\
\hline Hybrid & $183.529 \mathrm{a}$ & $103.059 \mathrm{a}$ & $1.300 \mathrm{c}$ & $0.950 \mathrm{a}$ \\
\hline
\end{tabular}

*Data were reported as means \pm standard error. Standard errors were represented as vertical bars which were the mean of three values $(\mathrm{n}=3)$; letters in common indicate no significant differences assessed by Fisher LSD test $(\mathrm{P} \leq 0.05)$ after performing ANOVA.

Table 3. Antioxidant enzymes of an interspecific line H. annuus x H. Nuttallii*

\begin{tabular}{|c|c|c|c|c|}
\hline \multirow{2}{*}{ Parents and hybrid } & \multicolumn{2}{|c|}{ CAT (units mg pr-1 $\mathrm{min}^{-1}$ ) } & \multicolumn{2}{|c|}{ GPO (units mg pr ${ }^{-1} \mathrm{~min}^{-1}$ ) } \\
\hline & Leaves & Ray flowers & Leaves & Ray flowers \\
\hline H. annuus & $16.250 \mathrm{~b}$ & $13.140 \mathrm{~b}$ & $92.498 \mathrm{a}$ & $31.010 \mathrm{a}$ \\
\hline H. nuttallii & $5.691 \mathrm{a}$ & $3.513 \mathrm{c}$ & $476.095 \mathrm{c}$ & $200.526 b$ \\
\hline \multirow[t]{3}{*}{ Hybrid } & $15.286 \mathrm{a}$ & $4.651 \mathrm{a}$ & $294.057 b$ & $23.217 \mathrm{a}$ \\
\hline & \multicolumn{2}{|c|}{ APX $\left(\mu \mathrm{mol} \mathrm{ASC} \mathrm{mg} \mathrm{pr}{ }^{-1} \mathrm{~min}^{-1}\right.$} & \multicolumn{2}{|c|}{ SOD (units $\mathrm{mg} \mathrm{pr}^{-1} \mathrm{~min}^{-1}$ ) } \\
\hline & Leaves & Ray flowers & Leaves & Ray flowers \\
\hline H. annuus & $0.720 \mathrm{~b}$ & $0.400 \mathrm{c}$ & $56.422 b$ & $36.154 b$ \\
\hline H. nuttallii & $0.109 \mathrm{a}$ & $0.158 b$ & $13.253 \mathrm{a}$ & $57.385 c$ \\
\hline Hybrid & $0.068 \mathrm{a}$ & $0.080 \mathrm{a}$ & $13.527 \mathrm{a}$ & $9.803 \mathrm{a}$ \\
\hline
\end{tabular}

*Data were reported as means \pm standard error. Standard errors were represented as vertical bars which were the mean of three values ( $\mathrm{n}=3$ ); letters in common indicate no significant differences assessed by Fisher LSD test $(\mathrm{P} \leq 0.05)$ after performing ANOVA.

Determination of the Level of CAT, SOD, GPO, and $A P X$ in the Three Sunflower Genotypes

Analysis of CAT activity revealed differences between three genotypes, which were evident both in the leaves and ray flowers (Table 3 ). The most striking of these differences was the activity of CAT in perennial $H$. nuttallii. GPO activities in the leaves for three selected genotypes were higher than that these in the ray flowers, despite of the almost equal phenolic content in both plant organs (Table 3 ). The highest value was established in the leaves of $H$. nuttallii. However, the GPO activity of hybrid line was intermediate of two parental genotypes. In common sunflower $H$. annuus, SOD-activity was statistically higher than activities recorded in wild sunflower and HA-Hnutt line (Table 3). There was no substantial difference in the level of SOD in the leaves sample of $H$. nuttallii and hybrid line. However, in rayflowers of hybrid plants, the level of SOD was strongly reduced compared with both parental genotypes. Common sunflower showed the highest APX activity in the leaves when compared with $H$. nuttallii and hybrid line (Table 3). Similar trend revealed the APX activity in the ray flowers. Hybrid, however, revealed the lowest APX activity in the leaves than either parent.

\section{Discussion}

In Helianthus crop breeding programs, wild relatives have been evaluated as genetic resources to develop new cultivars with potential traits that could lead to improvements (Davey et al, 2010; Breton et al, 2012; Zhang et al., 2017). Wide hybridization has been performed between common sunflower, H. annuus and its wild relatives to produce enhanced sunflower germplasms with high yield, high oil content, and desirable fatty acid concentration, as well as novel resistance genes for diseases and insects (Seiler and Marek, 2011; Kaya, 2014; Zhang et al., 2017). In this view, hybridization may play a creative role in providing the genetic "row material" required to support practical breeding strategies, and also to study the genetic relationships between species in the genus Helianthus. Herewith, we examined the lategeneration fitness consequences of hybridization between the common sunflower, $H$. annuus and wild perennial diploid H. nuttallii. According to Johansen-Morris and Latta (2006), the fitness of later generation recombinant inbred lines (RILs) derived from the cross reflects both the loss of early generation heterozygosity as well as disruption of any collapsed gene complexes present in the parents. Herewith, we have presented a recombinant inbred line (RIL) easily distinguished from both common sunflower and wild perennial parents that will likely be used in sunflower breeding.

As in other studies (Faure et al., 2002; VassilevskaIvanova et al., 2003; Breton et al., 2012), the interspecific hybridization affects a wide range of vegetative and reproductive traits. In terms of phenotype, the common sunflower, $H$. annuus appeared to be dominant since hybrid $H$. annuus $\times H$. nuttallii matched closely the female parent for some $H$. annuus-line morphological 
traits. The most remarkable feature observed was the vigorous plant habit that manifests itself in measurable morphological characters such as increment plant height, stem diameter and diameter of the head, thus, suggesting the pleiotropic effect of hybridization. Further, the growth habit and flower features had a clearly intermediate character, thus, indicating that characters from both parents are being expressed. Morphological data are consistent with several studies in that the morphological intermediacy of the hybrids between the common sunflower, $H$. annuus and several of its congeners, including H. mollis (Faure et al., 2002; VassilevskaIvanova et al., 2005; Breton et al., 2012), H. argophyllus (Vassilevska-Ivanova et al., 1998), and wild H. annuus, $H$. petiolaris, $H$. bolanderi (Vassilevska-Ivanova et al., 2001) has been documented.

Along with the morphological and reproductive traits, some biochemical characteristics related to antioxidant activity were associated to wide hybridization. The comparison of hybrid line and both parental species revealed that antioxidant capacity and the level of antioxidant enzymes such as CAT, SOD, GPO, and APX were altered by the interspecific hybridization to a different extent. It was observed that, among the analyzed biochemical parameters FRAP, ascorbic acid, the amount of total tocopherols, CAT, and GPO content were mostly intermediate. Among these parameters, the total content of tocopherols seems to be of practical interest considering its high antioxidant potential. It was established that the sunflower oil is the richest in $\alpha$ tocopherol which is the main compound among the tocopherol homologs with the highest biological activities (Seiler and Marek, 2017). This fact could contribute to reinforcing the idea that interspecific hybridization can be a potential tool to improve vitamin $E$ status of the sunflower oils rich in monounsaturated fatty acids. However, further studies are needed to characterize the composition of hybrid oil and to assess its potential as a source of health-promoting bioactive compounds.

The present study indicated significant differences in antioxidant enzymes activity among three investigated genotypes. It was reported that very few studies have attempted to determine the mechanisms behind the patterns of chemical variation, thus reducing ability to predict which hybrids will be more or less variable (Orians, 2000). Also, genetic studies to ascertain whether the pattern of chemical variation arose as a direct byproduct of hybridization or whether they evolved via other mechanisms, for example, the type of divergence is necessary to be performed. In the leaf samples of HAHnutt line, the total phenolic and flavonoids content altered to a different extent (Table 2); the total phenolic content and the flavonoids were higher than these in both parents. In the current study, the antioxidant level of phenols and flavonoids is an indication that both characteristics might be hardly useful as biochemical diagnostic markers for preliminary evaluation of the hybridization events. So, in relation to the sunflowers $(H$. annuus and its wild relatives), the identification of specific biochemical markers that verified the hybrid origin of the plants is needed to be investigated. Thus, we can come closer to mechanisms of wide hybridization and generalizations of methods for testing of experimental hybrids in the selection studies.

In conclusion, it is possible to produce fertile hybrid plants from crosses between common sunflower, $H$. annuus and wild perennial diploid species $H$. nuttallii. Morphological and biochemical characters provide substantial evidence that $H$. nuttallii is involved in hybridization process. Outcomes of hybridization between both Helianthus species show the formation of a stable single headed line with extreme plant habit. Our results suggest that the genetic diversity between two species is not a strong barrier to the hybrid formation. Nevertheless, more research is needed to elucidate the real potential of wild sunflower germplasms and their introduction into breeding programs to develop high performance cultivars.

\section{Conflict of Interest}

The authors declare no conflict of interest.

\section{References}

Beers Jr RF, Sizer IW. 1952. A spectrophotometric method for measuring the breakdown of hydrogen peroxide by catalase. Journal of Biological Chemistry, 195 (1):133-140.

Bradford MM. 1976. A rapid and sensitive method for the estimation of microgram quantities of protein utilizing the principle of protein-dye binding. Analytical Biochemistry, 72: 248-254.

Breton C, Gil A, Wargnier J, Seriyes H, Berville A. 2012. Transfer of architectural traits from perennial Helianthus mollis Lam. to sunflower (H. annuus L.) and localisation of introgression. Euphytica, 186 (2): 557-572.

Davey MR, Masood J. 2010. Sunflower (Helianthus annuus L.): genetic improvement using conventional and in vitro technologies. Journal of Crop Improvement, 24 (4): 349391.

Faure N, Serieys H, Cazaux E, Kaan F, Berville A. 2002. Partial hybridization in wide crosses between cultivated sunflower and the perennial helianthus species $H$. mollis and $H$. orgyalis. Annals of Botany, 89 (1): 31-39.

Fambrini M, Bertini D, Pugliesi C. 2003. The genetic basis of a mutation that alters the floral symmetry in sunflower. Annals of Applied Biology, 143 (3): 341-347.

Feng Z, Liu X, Cai G, Seiler J, Gulya TJ, Rashid KY, Jan CC (2007). Transferring Sclerotinia resistance genes from wild Helianthus into cultivated Sunflower. J North Dakota State University, USDA-ARS, ND 58105: 1-3.

Giannopolitis CN, Ries SK. 1977. Superoxide dismutases I. Occurrence in higher plants. Plant Physiology, 59(2): 309314.

Johansen-Morris AD, Latta RG. 2006. Fitness consequences of hybridization between ecotypes of Avena barbata: hybrid breakdown, hybrid vigor, and transgressive segregation. Evolution, 60 (8): 1585-1595.

Kaya Y. 2014. Sunflower. In Alien Gene Transfer in Crop Plants, Pratap, A. and J. Kumar, (Eds.). Springer, v. 2: 281300.

Liu Z, Seiler GJ, Gulya TJ, Feng J, Rashid KY, Cai X, Jan CC. 2017. Triploid production from interspecific crosses of two diploid perennial Helianthus with diploid cultivated sunflower (Helianthus annuus L.). G3 (Bethesda), 37 (4): 1097-1108.

McKersie BD, Leshem YY. 1994. Stress and stress coping in cultivated plants. Kluwer Academic Publishes, Dordrecht. pp. 256 
Nakano Y, Asada K. 1981. Hydrogen peroxide is scavenged by ascorbate-specific peroxidases in spinach chloroplasts. Plant and Cell Physiology, 22(5):867-880.

Orians CM. 2000. The effect of hybridization in plant on secondary chemistry: implications for the ecology and evolution of plant-herbivore interactions. American Journal of Botany, 87 (12): 1749-1756.

Pfeffer H, Dannel F, Rumheld V. 1998. Are there connection between phenol metabolism, ascorbate metabolism and membrane integrity in leaves of boron-deficient sunflower plants? Physiologia Plantarum, 104: 479-485.

Plewa MJ, Smith SR, Wagner ED. 1991. Diethyldithiocarbamate suppresses the plant activation of aromatic amines into mutagens by inhibiting tobacco cell peroxidase. Mutation Research, 247(1): 57-64.

Schilling EE. 2006. Helianthus. Flora of North America Committee. Oxford University Press, New York, pp: 141169.

Seiler G, Marek F. 2011. Germplasm resources for increasing the genetic diversity of global cultivated sunflower. Helia, 34 (55): 1-20.

Seiler G, Qi LL, Marek LF. 2017. Utilization of sunflower crop wild relatives for cultivated sunflower improvement. Crop Science, 57: 1083-1101.

Stebbins JC, Winchell CJ, Constable JVH. 2013. Helianthus winteri (Asteraceae), a new perennial species from the southern Sierra Nevada foothills, California. Aliso: A Journal of Systematic and Evolutionary Botany, 31(1):1924.

Tepe B, Sokmen M, Akpulat HA, Sokmen A. 2006. Screening of the antioxidant potentials of six Salvia species from Turkey. Food Chemistry, 95(2): 200-204.

Urbanek H, Kuzniak-Gebarowska E, Herka K. 1991. Elicitation of defense responses in bean leaves by Botrytis cinerea polygalacturonase. Acta Physiologiae Plantarum, 13:43-50.

Vassilevska-Ivanova R, Tcekova Z, Lidansky T. 1998. Hybridization of cultivated sunflower Helianthus annuus L. with silver-leaf sunflower $H$. argophyllus Torr. \& Gray. Comptes rendus de l'Academie bulgare des Sciences, 51(1): $109-112$.
Vassilevska-Ivanova R, Tcekova Z, Lidansky T. 2001. Interspecific hybridization between cultivated sunflower $H$. annuus L. and some annual Helianthus species: wild $H$. annuus, $H$. petiolaris and $H$. bolanderi. Comptes rendus de l'Academie bulgare des Sciences, 54(6): 59 - 64.

Vassilevska-Ivanova R, Tcekova Z. 2003. Evaluation and genetics study of $F_{1}$ sunflower hybrids. Comptes rendus de l'Academie bulgare des Sciences, 56 (5): 81 - 86.

Vassilevska-Ivanova R, Naidenova N. 2005. Hybridization in the perennial sunflowers: Helianthus annuus x Helianthus mollis. Genetics and Breeding, 34(3-4): 33-38.

Vassilevska-Ivanova R, Kraptchev B, Stancheva I, Geneva M. 2013. A compact sunflower line produced after cross Helinathus annuus $\mathrm{x}$ Verbesina encelioides. Central European Journal of Biology, 8 (5): 492-498.

Vassilevska-Ivanova R, Kraptchev B, Stancheva I, Geneva M, Iliev I, Georgiev G. 2014. Utilization of related wild species (Echinacea purpurea) for genetic enhancement of cultivated sunflower (Helianthus annuus L.). Turkish Journal of Agriculture and Forestry, 38 (1): 15-22.

Vassilevska-Ivanova R, Kraptchev B, Shtereva L. 2015. An intergeneric hybrid line produced after cross Helianthus annuus x Echinacea purpurea. Genetic Recourses and Crop Evolution, 62(6): 829-836.

Warner RM, Walworth AE. 2010. Quantitative inheritance of crop timing traits in interspecific hybrid Petunia populations and interactions with crop quality parameters. Journal of Heredity, 101(3): 308-316.

Zhang ZW, Ma G, Zhao J, Qi L. 2017. Discovery and introgression of the wild sunflower-derived novel downy mildew resistance gene $\mathrm{Pl}_{19}$ in confection sunflower (Helianthus annuus L.). Theoretical and Applied Genetics, 130 (1): 29-39.

Zhishen J, Mengcheng T, Jianming W. 1999. The determination of flavonoids contents in mulberry and their scavenging effects on superoxide radicals. Food Chemistry, 64 (4):555559 . 